\title{
Emergency endoscopic exploration of a pancreatic pseudocyst to retrieve a migrated pigtail stent
}

Endoscopic ultrasound (EUS)-guided drainage of pancreatic pseudocyst using double-pigtail plastic stents is a well-established technique with a high success rate ( $95 \%-100 \%)$. Early adverse events, namely bleeding and perforation, occur in up to $5 \%$ of the procedure [1-3].

A 38-year-old woman with a history of alcohol abuse was admitted to hospital because of dysphagia, abdominal pain, and vomiting. Computed tomography (CT) scan showed an encapsulated pancreatic fluid collection, and therefore EUS-guided drainage was performed. EUS-guided access to the collection was achieved with a 19-gauge needle ( $\mathbf{F i g . 1}$ ) and a first guidewire was inserted. A cystotome was used, followed by hydrostatic dilation up to $8 \mathrm{~mm}$. After insertion of a second guidewire, a double-pigtail 7-Fr, 5-cm plastic stent was delivered, but immediately after deployment the stent spontaneously migrated inside the collection ( Fig.2). Blind retrieval was attempted without success with both foreign-body forceps and Dormia basket ( $\mathbf{F i g . 3}$ ). Therefore a lumen-apposing metal stent (LAMS) was thendeployed ( $\triangleright$ Fig.4), and a slim gastroscope was advanced inside the pseudocyst ( $\triangleright$ Fig.5). Exploration of the cavity allowed location of the migrated pigtail stent and retrieval using a pediatric biopsy forceps ( $\triangleright$ Video 1 ). Finally, a duodenoscope was used to remove the LAMS and to insert two 10-Fr double-pigtail plastic stents ( $\bullet$ Fig. $\mathbf{6}$ ). Inadvertent plastic stent migration inside a cavity is an adverse event that may be difficult to manage. Massive dilation of the tract is not recommended as first-line treatment because of the risk of perforation. Deployment of a LAMS seems a safe and effective option for guaranteeing sustained access to the cavity and allowing the use of a slim endoscope to explore the cavity. In our patient the pseudocyst was not infected; therefore we decided to remove the

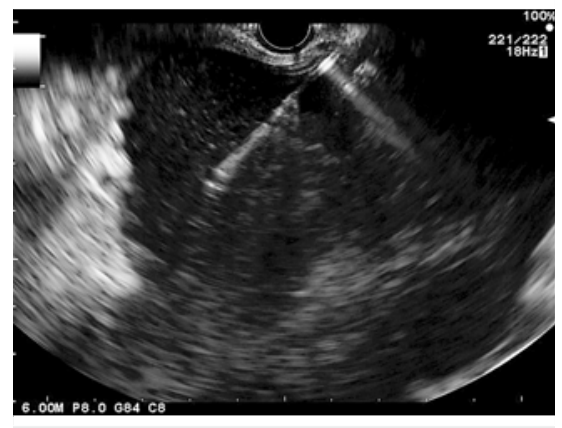

- Fig. 1 Endoscopic ultrasound (EUS)guided puncture of a pancreatic pseudocyst using a 19-G needle.

metal stent in order to allow an early oral diet and reduce the risk of superinfection caused by food stasis. Nonetheless, use of a LAMS might prove very useful in the management of adverse events related to drainage of pseudocysts.

Endoscopy_UCTN_Code_CPL_1AK_2AD
Competing interests

None

The Authors

Gianfranco Donatelli ${ }^{1}$, Jean-Loup Dumont ${ }^{1}$, Fabrizio Cereatti ${ }^{2}$, Thierry Tuszynski ${ }^{1}$,

Giovanni Calogero ${ }^{1}$, Bertrand M. Vergeau ${ }^{1}$, Bruno Meduri'

1 Unité d'Endoscopie Interventionnelle, Ramsay Générale de Santé, Hôpital Privé des Peupliers, Paris, France

2 Digestive Endoscopy and Gastroenterology Unit, A.O. Istituti Ospitalieri di Cremona, Cremona, Italy

\section{Corresponding author}

\section{Gianfranco Donatelli, MD}

Unité d'Endoscopie Interventionnelle, Ramsay Générale de Santé, Hôpital Privé des Peupliers, 8 Place de l'Abbé G. Hénocque, 75013, Paris, France

Fax: +33-1-44165615

donatelligianfranco@gmail.com

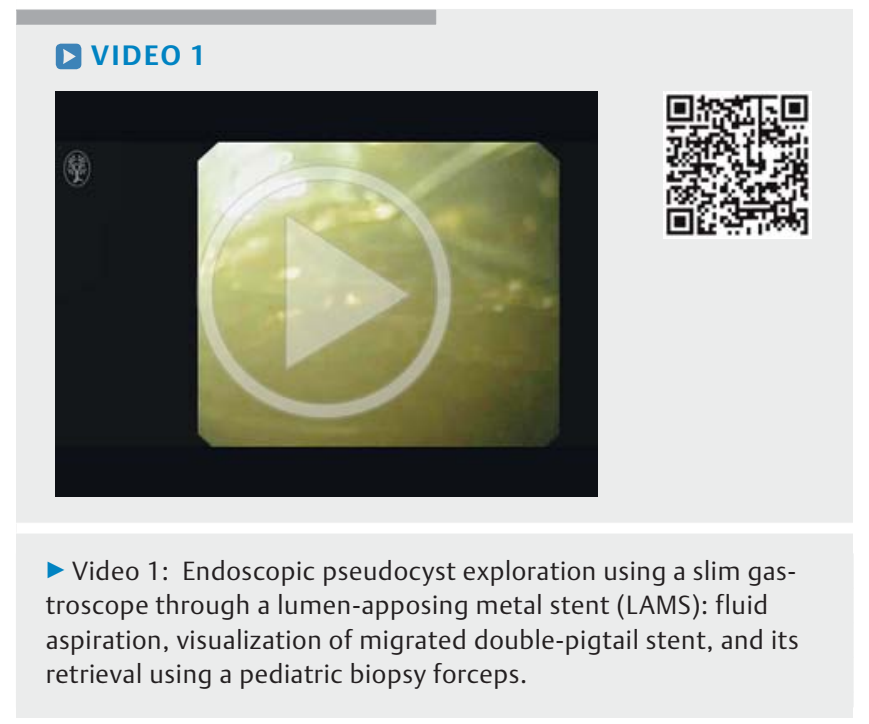



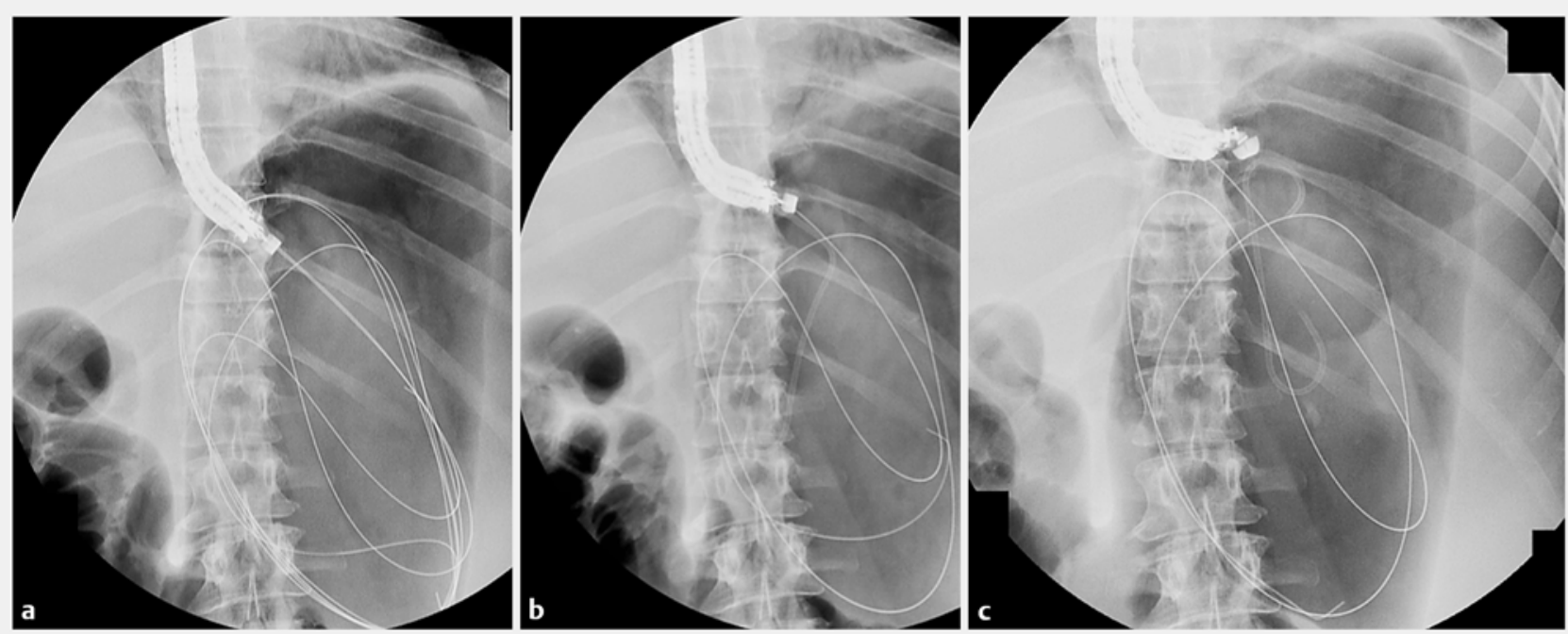

- Fig. 2 a Double guidewires inside the pseudocyst. b Deployment of 5-cm 7-Fr double-pigtail plastic stent. c Immediately, the double-pigtail stent spontaneously migrated inside the cavity.

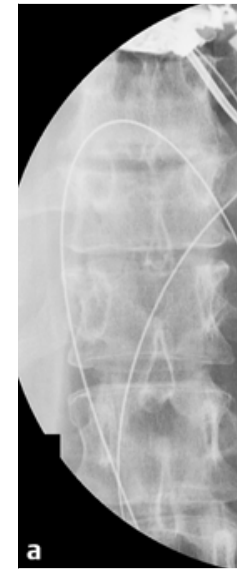

Fig. 3 Attempts at blind retrieval of the migrated double-pigtail stent, using: a foreignbody forceps, and $\mathbf{b}$ a Dormia basket.
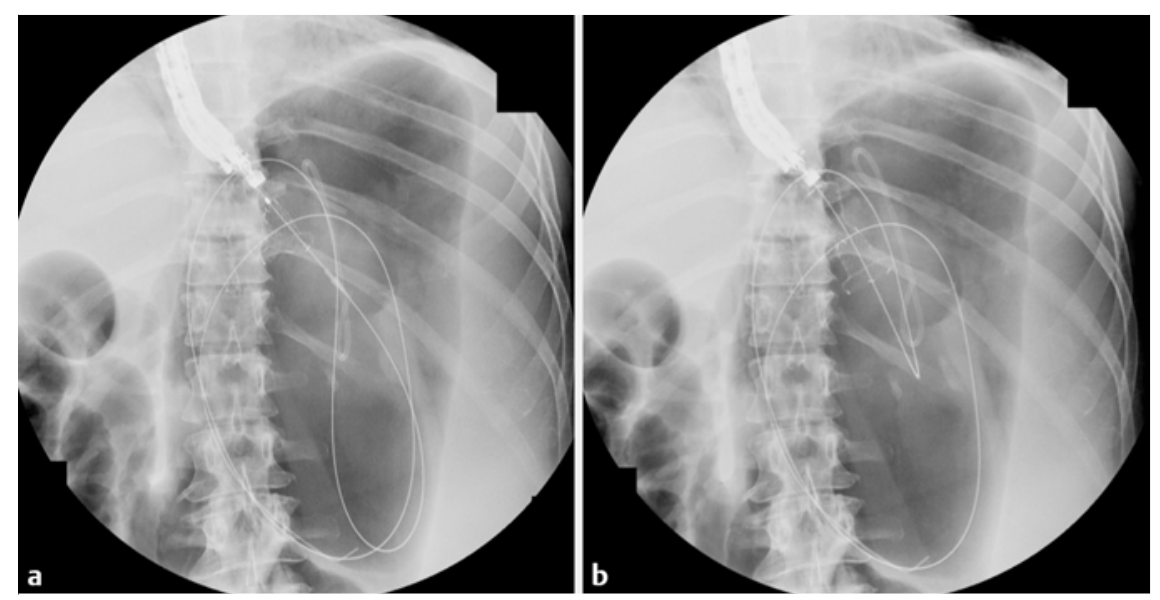

- Fig. 4 a, b Deployment of a lumen-apposing metal stent (LAMS) to allow sustained access to the cavity of the pancreatic pseudocyst.

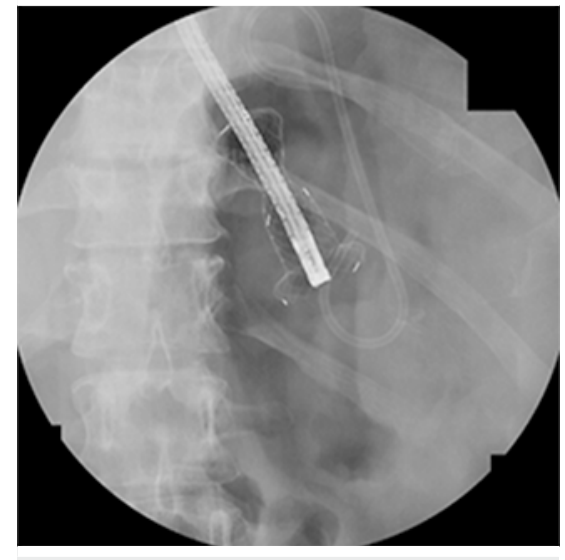

> Fig. 5 A gastroscope was advanced through the lumen-apposing metal stent (LAMS) into the pseudocyst cavity.


- Fig. 6 Insertion of two 10-Fr, 5-cm double-pigtail plastic stents to drain the pancreatic pseudocyst. 


\section{References}

[1] Tyberg A, Karia K, Gabr M et al. Management of pancreatic fluid collections: A comprehensive review of the literature. World J Gastroenterol 2016; 22: 51 - 53

[2] Bang JY, Hasan MK, Navaneethan U et al. Lumen apposing metal stents (LAMS) for drainage of pancreatic fluid collections: When and for whom? Dig Endosc 20.05 2016: Epub ahead of print. DOI: $10.1111 /$ den. 12681

[3] Saftoiu A, Vilmann A, Vilmann P. Endoscopic ultrasound-guided drainage of pancreatic pseudocysts. Endosc Ultrasound 2015; 4: $319-323$
Bibliography

DOI http://dx.doi.org/10.1055/s-0042-122143 Endoscopy 2017; 49: E51-E53

(c) Georg Thieme Verlag KG

Stuttgart · New York

ISSN 0013-726X 